\title{
Crude Oil-Brine-Rock Interactions in Tight Chalk Reservoirs: An Experimental Study
}

\author{
Samira Mohammadkhani *(D), Benaiah U. Anabaraonye (D), Armin Afrough (D), Rasoul Mokhtari (D) \\ and Karen Louise Feilberg *
}

The Danish Hydrocarbon Research and Technology Centre, Technical University of Denmark, 2800 Kongens Lyngby, Denmark; bana@dtu.dk (B.U.A.); armafr@dtu.dk (A.A.); rasoulm@dtu.dk (R.M.)

* Correspondence: sm@geus.dk (S.M.); klfe@dtu.dk (K.L.F.)

Citation: Mohammadkhani, S.; Anabaraonye, B.U.; Afrough, A.; Mokhtari, R.; Feilberg, K.L. Crude Oil-Brine-Rock Interactions in Tight Chalk Reservoirs: An Experimental Study. Energies 2021, 14, 5360.

https://doi.org/10.3390/

en14175360

Academic Editor: Kunsang Lee

Received: 31 July 2021

Accepted: 24 August 2021

Published: 28 August 2021

Publisher's Note: MDPI stays neutral with regard to jurisdictional claims in published maps and institutional affiliations.

Copyright: (c) 2021 by the authors. Licensee MDPI, Basel, Switzerland. This article is an open access article distributed under the terms and conditions of the Creative Commons Attribution (CC BY) license (https:// creativecommons.org/licenses/by/ $4.0 /)$.

\begin{abstract}
We present a systematic study of crude oil-brine-rock interactions in tight chalk cores at reservoir conditions. Flooding experiments are performed on outcrops (Stevns Klint) as well as on reservoir core plugs from Dan field, the Ekofisk and Tor formations. These studies are carried out in core plugs with reduced pore volumes, i.e., short core samples and aged with a dynamic ageing method. The method was evaluated by three different oil compositions. A series of synthetic multicomponent brines and designed fluid injection scenarios are investigated; injection flow rates are optimized to ensure that a capillary-dominant regime is maintained. Changes in brine compositions and fluid distribution in the core plugs are characterized using ion chromatography and X-ray computed tomography, respectively. First, we show that polar components in the oil phase play a major role in wettability alteration during ageing; this controls the oil production behavior. We also show that, compared to seawater, both formation water and ten-times-diluted seawater are better candidates for enhanced oil recovery in the Dan field. Finally, we show that the modified flow zone indicator, a measure of rock quality, is likely the main variable responsible for the higher oil recoveries observed in Tor core samples.
\end{abstract}

Keywords: low salinity water; crude oil-brine-rock interactions; chalk; short core plug; core flooding

\section{Introduction}

Low-salinity water injection (LSWI) has shown improved oil recovery in both sandstone [1-5] and carbonate [6-8] reservoirs. Although the mechanisms behind the success of LSWI in carbonates have been studied extensively [9-14], decoupling the specific underlying mechanisms remains a challenge. To tackle this challenge, a systematic study of the crude oil-brine-rock (COBR) interactions for each reservoir is critical.

The initial reservoir wettability is a result of the chemical equilibrium established between rocks and reservoir fluids, due to millions of years of contact. The disequilibrium of the COBR system induced by the injection of a low salinity or modified salinity brine can lead to an increase in oil recovery $[10,15]$. Wettability alteration from this 'initial reservoir wetting state' has been reported as the main mechanism behind enhanced oil recovery (EOR) by LSWI $[15,16]$. Wettability alteration itself is an effect produced by other microscale mechanisms, such as surface ion exchange [17], changes in surface charge [18], double-layer expansion [19], and mineral dissolution [20]. Other proposed mechanisms for the enhanced oil recovery by LSWI include fines migration [21-23], the dissolution of crude oil polar components into the brine [24,25], enhancement of the viscoelasticity of the crude oil-brine interface [26], and flow diversion by emulsification $[23,27,28]$. There is still a need to determine which mechanism is primary at particular reservoir conditions with a specific COBR system [18].

One of the advantages of LSWI is that it can be integrated with other EOR methods in a hybrid process such as low-salinity water alternating $\mathrm{CO}_{2}$ flooding $\left(\mathrm{CO}_{2} \mathrm{LSWAG}\right)$ [29], lowsalinity polymer flooding [30], and surfactant improved low-salinity water flooding [31]. 
The combined method can benefit from both LSWI mechanisms such as wettability alteration and the mechanisms related to the second method, e.g., miscibility effect in $\mathrm{CO}_{2}$ LSWAG or oil viscosity reduction in combination with surfactant flooding [29].

The effect of a modified brine on oil recovery from core samples is routinely investigated by forced imbibition (core flooding) experiments and is often supplemented by spontaneous imbibition tests $[6,23,32-35]$. Spontaneous imbibition is governed primarily by capillary forces, while in forced imbibition experiments viscous forces prevail [36]. A large number of core flooding experiments-which can be time-consuming, costly, and challenging — are needed for upscaling reservoir models [37]. Standard core plugs, with lengths of 2 to 15 inches and diameters of 1 or 1.5 inches, are widely used in core flooding studies; experiments conducted on these standard core plugs typically take weeks to complete, especially when using tight carbonates samples $[19,38]$. Cores with reduced pore volumes can be used as alternatives [39] as they minimize experimental time and can be accomplished even with limited reservoir materials.

One of the time-consuming steps in core flooding experiments is the restoration of the initial wettability of rock during core preparation, known as ageing. Ageing protocols have been investigated at reservoir conditions to examine either the optimum crude oil-rock contact time in static conditions [40] or the flow rate and time of continuous injection in dynamic conditions [41]. Graue et al. (2002) investigated the wettability alteration of chalk samples as a function of the ageing method and reported that dynamic ageing was more effective in restoring the initial wettability than the static method [42]. They also concluded that shorter core plugs attained more homogeneous water saturation profiles during dynamic ageing compared to static methods [42]. Therefore, the reduced porevolume approach, together with dynamic ageing protocol, was implemented in the current study to be able to restore the wettability more efficiently.

Previous studies have investigated the role of brine chemistry [20,43], the oil phase [32], and rock chemistry individually or in combination, in a static manner. Examples include contact angle measurements or spontaneous imbibition tests [36]. Considering brine, rock, and oil interactions in designing experiments is important. Diluted seawater, for example, has been shown to have more impact on contact angle measurements [18] than on interfacial tension (IFT) $[23,27]$. This highlights the importance of a more comprehensive investigation of COBR interactions rather than pore scale experiments or fluid-fluid studies $[37,44]$. It is also important to note that the effect of LSWI is reservoir-specific. In other words, a specific injection sequence that is effective in one reservoir is not necessarily directly applicable to a new system.

In the current study, we aim to demonstrate the response of reservoir samples from the Dan field to LSWI at different stages of flooding. Seawater, diluted seawater, and formation water were injected systematically at reservoir conditions, and produced oil recovery curves were compared. To understand the effect of COBR individually, we investigate three different oil compositions: hexadecane, stearic acid-hexadecane, and reservoir crude oil. We selected reservoir core plugs from both the Ekofisk and Tor formations, as well as outcrop Stevns Klint chalk samples.

\section{Materials and Method}

\subsection{Materials}

\subsubsection{Oil}

Hexadecane (analytical grade, Merck, Darmstadt, Germany) was used as a model oil for the first core flooding experiment; reservoir crude oil was used for the rest of the experiments, except the second one. In the second experiment, a hexadecane-stearic acid mixture was used to mimic the acid number of the crude oil (i.e., $0.5 \mathrm{mg} \mathrm{KOH} / \mathrm{g}$ oil); $0.48 \mathrm{~g}$ stearic acid (99\% purity, Sigma-Aldrich) was added to $250 \mathrm{~mL}$ of hexadecane. Acids are thought to play a key role in wettability alteration and modified salinity water injection [15]. The viscosity of the model oil was $2.15 \mathrm{cP}$. The density and viscosity of the crude oil used in these experiments $\left(\right.$ at $70{ }^{\circ} \mathrm{C}$ ) were $0.83 \mathrm{~g} / \mathrm{mL}$ and $3.04 \mathrm{cP}$, respectively; these were 
measured by an Anton-Paar viscosity meter. Before use, the crude oil was filtered with a 7-micron filter at $70{ }^{\circ} \mathrm{C}$. The Dan field crude oil SARA (saturates, aromatics, resins, and asphaltenes) fractions were as follows: $73.3 \%$ saturates, $15.3 \%$ aromatics, and $11.5 \%$ resins and asphaltenes, with the asphaltene fraction being too small to separate from resins.

\subsubsection{Brine}

Brines were synthesized gravimetrically by dissolving salts $\left(\mathrm{NaCl}, \mathrm{Na}_{2} \mathrm{SO}_{4}, \mathrm{KCl}\right.$, $\mathrm{MgCl}_{2} \cdot 6 \mathrm{H}_{2} \mathrm{O}, \mathrm{CaCl}_{2} \cdot 2 \mathrm{H}_{2} \mathrm{O}, \mathrm{SrCl}_{2} \cdot 6 \mathrm{H}_{2} \mathrm{O}, \mathrm{BaCl}_{2} \cdot 2 \mathrm{H}_{2} \mathrm{O}, \mathrm{CaCO}_{3}$, and $\mathrm{NaNO}_{3}$ ) from Merck (99\% purity) in ultrapure deionized water. Brine concentrations are shown in Table 1. The formation water composition was reported in private communication with the field operator, and the mean seawater composition as reported by the Danish environmental authorities. In this table, FW stands for formation water, SW for seawater, and DSW (1/5), DSW (1/10), and DSW (1/20) for 5, 10, and 20-times-diluted seawater, respectively, where the fraction in the parenthesis represents the dilution factor with deionized water. In experiment 5 , DSW $(1 / 10)$ was spiked with two times more sulfate, shown as DSW $(1 / 10)+2 S$. DSW $(1 / 10)+2 S+4 \mathrm{Mg}$ stands for 10-times-diluted seawater spiked with 2 times more sulfate and 4 times more magnesium. DSW $(1 / 10)+\mathrm{NO}_{3}{ }^{2-}$ shows spiked diluted seawater with 500 ppm sodium nitrate. The viscosity of formation brine was measured to be $0.47 \mathrm{cP}$ at $70^{\circ} \mathrm{C}$.

Table 1. Calculated ion concentrations of synthetic brines in core flooding experiments according to Danish North Sea reservoir fluids and seawater.

\begin{tabular}{|c|c|c|c|c|c|c|c|c|}
\hline Ion (mg/L) & FW & SW & DSW (1/5) & DSW (1/10) & DSW (1/20) & $\begin{array}{l}\text { DSW (1/10) } \\
+2 S\end{array}$ & $\begin{array}{l}\text { DSW (1/10) } \\
+2 S+4 \mathrm{Mg}\end{array}$ & $\begin{array}{l}\text { DSW (1/10) } \\
+\mathrm{NO}_{3}{ }^{2-}\end{array}$ \\
\hline $\mathrm{Na}^{+}$ & 27,290 & 10,750 & 2150 & 1080 & 540 & 1218 & 1218 & 1269 \\
\hline $\mathrm{Ca}^{2+}$ & 1470 & 410 & 82 & 41 & 20.5 & 34 & 34 & 37 \\
\hline $\mathrm{Mg}^{2+}$ & 592 & 1100 & 219 & 109 & 55 & 128 & 512 & 128 \\
\hline $\mathrm{K}^{+}$ & 250 & 400 & 80 & 40 & 20 & 31 & 31 & 40 \\
\hline $\mathrm{Ba}^{2+}$ & 0.56 & 0 & 0 & 0 & 0 & 0 & 0 & 0 \\
\hline $\mathrm{Sr}^{2+}$ & 140 & 20 & 4 & 2 & 1 & 2 & 2 & 2 \\
\hline $\mathrm{Cl}^{-}$ & 46,500 & 19,350 & 3870 & 1940 & 970 & 1936 & 3057 & 1934 \\
\hline $\mathrm{CO}_{3}^{-}$ & 0 & 0 & 0 & 0 & 0 & 0.4 & 0.4 & 5.2 \\
\hline $\mathrm{HCO}_{3}{ }^{-}$ & 0 & 65 & 13 & 6.5 & 3 & 0 & 0 & 0 \\
\hline $\mathrm{SO}_{4}^{2-}$ & 290 & 2000 & 400 & 200 & 100 & 561 & 561 & 281 \\
\hline $\mathrm{NO}_{3}^{-}$ & 0 & 0 & 0 & 0 & 0 & 0 & 0 & 500 \\
\hline TDS (g/L) & 80.68 & 39.34 & 7.87 & 3.93 & 1.97 & 4.52 & 7.73 & 4.80 \\
\hline $\begin{array}{c}\text { Ionic } \\
\text { strength } \\
(\mathrm{mol} / \mathrm{L})\end{array}$ & $13.8 \times 10^{-1}$ & $6.65 \times 10^{-1}$ & $1.33 \times 10^{-1}$ & $6.66 \times 10^{-2}$ & $3.34 \times 10^{-2}$ & $7.81 \times 10^{-2}$ & $1.26 \times 10^{-1}$ & $7.77 \times 10^{-2}$ \\
\hline
\end{tabular}

\subsubsection{Core Plugs}

Reservoir core plugs were taken from two different wells. Reservoir, formation, well names, and measured depth of each core slice can be found in Table 2. Figures 1 and 2 show the petrophysical logs of the two wells showing the depths from where core plugs were taken. Core plugs B-1 and B-2 were extracted from MFB-07 (Ekofisk formation) while Core plug C-1 was extracted from MFF-19P (Tor formation). These core plugs have $S_{w i}$ between $20-40 \%$. The most homogeneous core plugs, i.e., without any obvious open fracture, were selected after evaluating CT images of different core slices. The porosity and permeability of the clean core slices were measured by a Vinci Poro-perm instrument before flooding studies. The physical characteristics of core slices including porosity, permeability, and $S_{w i}$ are shown in Table 3. 
Table 2. Rock materials, well name, and depth of core plugs.

\begin{tabular}{cccccc}
\hline Experiment & Reservoir-Formation & Core Plug * & Well Name & Measured Depth (ft) & $\begin{array}{c}\text { Geological } \\
\text { Position }\end{array}$ \\
\hline $1,2,3$ & Outcrop-Stevns Klint & A-1, A-2, A-3 & Outcrop & - & - \\
$4,5,6$ & Dan-Ekofisk & B-1, B-2 & MFB-7 & 7399 & D1A Base \\
$7,8,9$ & Dan-Tor & C-1 & MFF-19P & 8890 & M1B2 \\
\hline
\end{tabular}

${ }^{*} \mathrm{~A}, \mathrm{~B}$, and $\mathrm{C}$ refer to the main core plug names and the number after refers to the specific slice from the core plug. Some of the core slices were used in more than one experiment.

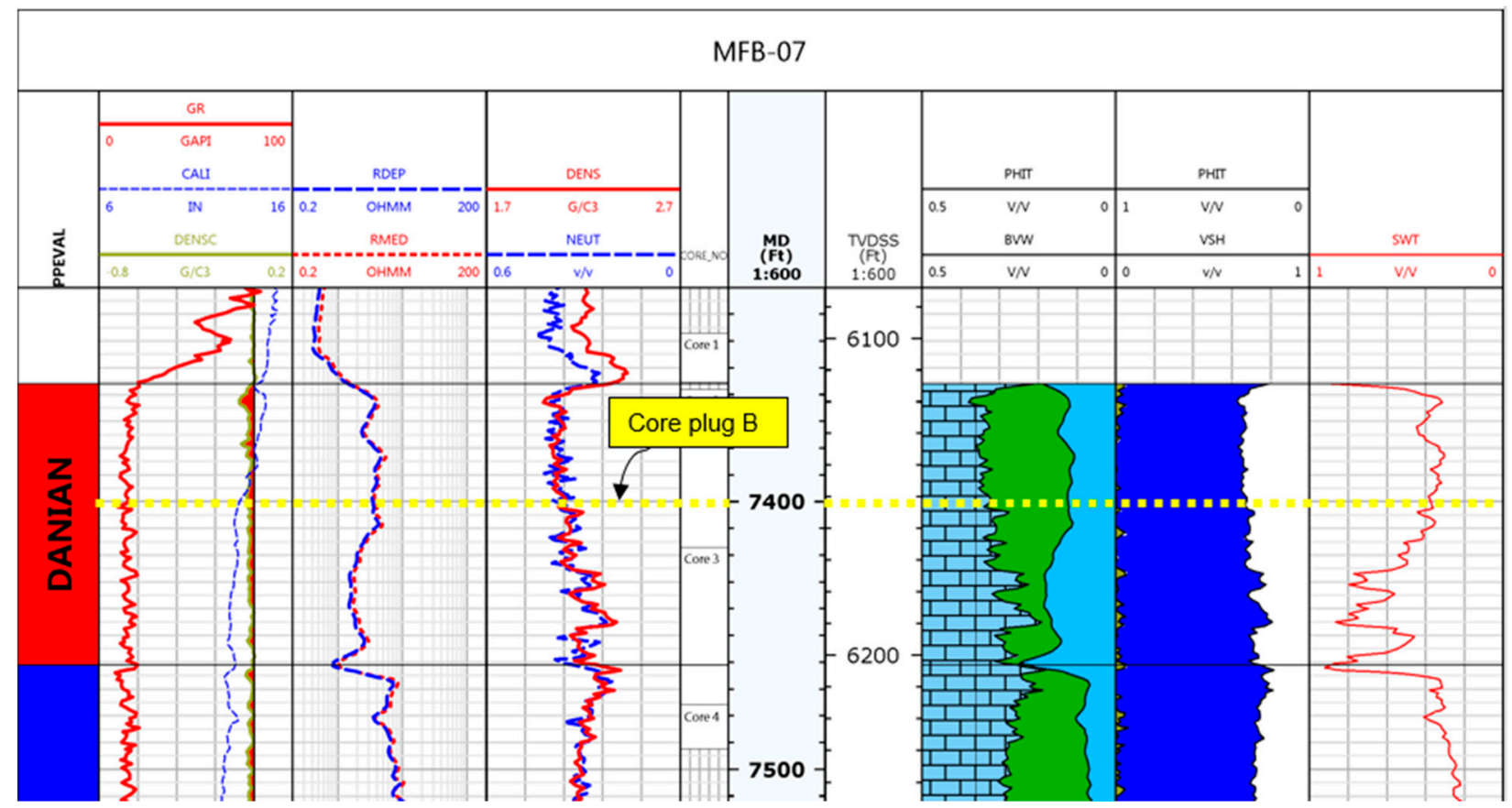

Figure 1. The measured depth (7399 ft) of core plug B from well MFB-7, Danian age, Ekofisk formation. The slices from this core plug were used in experiments 4 to 6 .

Table 3. Petrophysical characteristics of core plugs. Length L, diameter D, permeability K, and porosity $\Phi$ were measured before flooding studies; pore volume PV, and initial water saturation $\mathrm{S}_{\mathrm{wi}}$.

\begin{tabular}{cccccccc}
\hline Exp. & $\begin{array}{l}\text { Core } \\
\text { Plug }\end{array}$ & $\mathbf{L}(\mathbf{c m})$ & $\mathbf{D}(\mathbf{c m})$ & $\mathbf{K}(\mathbf{m D})$ & $\mathbf{\Phi ~ ( \% )}$ & $\mathbf{P V}(\mathbf{c c})$ & $\mathbf{S}_{\mathbf{w i}}(\mathbf{\%})$ \\
\hline 1 & A-1 & 1.57 & 3.66 & 3.04 & 47.4 & 07.8 & 22.1 \\
2 & A-2 & 1.93 & 3.68 & 3.85 & 48.8 & 10.0 & 08.0 \\
3 & A-3 & 1.58 & 3.65 & 3.77 & 50.8 & 08.4 & 22.4 \\
4 & B-1 & 1.09 & 3.74 & 0.54 & 39.1 & 04.7 & 17.0 \\
5 & B-2 & 1.08 & 3.76 & 0.64 & 42.5 & 05.1 & 19.6 \\
6 & B-2 & 1.08 & 3.76 & 0.49 & 42.5 & 05.1 & 23.5 \\
7 & C-1 & 1.54 & 3.79 & 1.13 & 36.4 & 06.3 & 21.7 \\
8 & C-1 & 1.54 & 3.79 & 1.18 & 38.8 & 06.7 & 33.1 \\
9 & C-1 & 1.54 & 3.79 & 1.27 & 38.8 & 06.7 & 35.1 \\
\hline
\end{tabular}




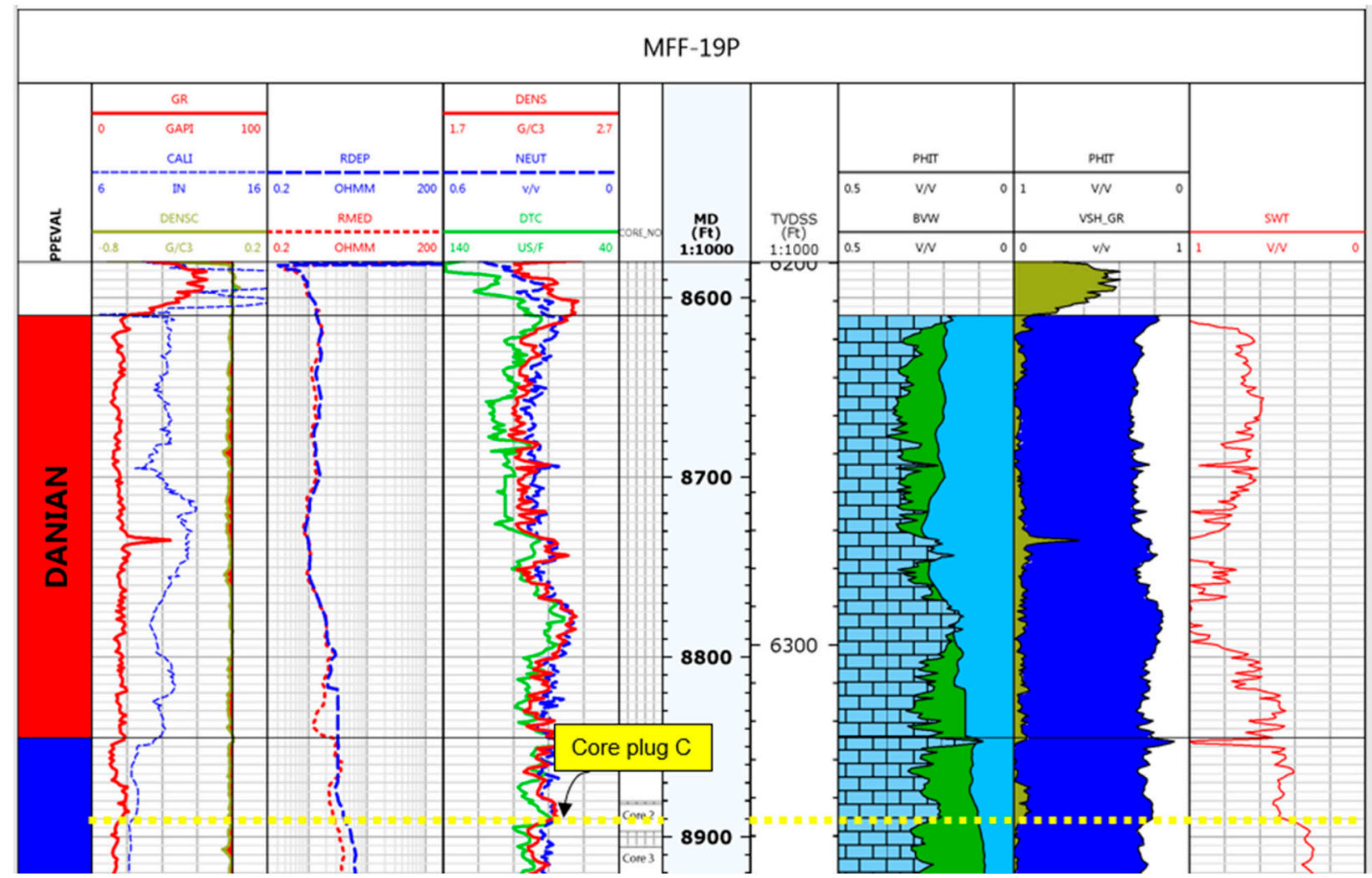

Figure 2. The measured depth $(8890 \mathrm{ft})$ of core plug C from well MFF-19P, Maastrichtian age, Tor formation. A slice from this core plug was used in experiments 7 to 9 .

Although the Danish North Sea chalk is a mono-mineralic carbonate rock that consists $80-90 \%$ calcite $\left(\mathrm{CaCO}_{3}\right)$ with less amounts of clay minerals, the amount of clay varies slightly between the Tor and Ekofisk formations. The Danian Ekofisk formation is more rich in silica compared to the underlying Maastrichtian Tor formation and makes up a more heterogeneous and overall poorer reservoir interval in many of the producing fields in the Danish Central Graben [45,46]. Røgen and Fabricius (2002) investigated fifty-nine Tor and Ekofisk formation chalk samples from five North Sea chalk reservoirs. All contained quartz and clay minerals, most commonly kaolinite and smectite, with trace amounts of illite. The clay content ranges from $0.1 \mathrm{wt} \%$ to $3 \mathrm{wt} \%$ in the Tor formation and can be as high as $21 \mathrm{wt} \%$ in the Ekofisk tight zone [47]. The specific surface area of Danish North chalk is well studied and modelled. The specific surface area of pure calcite powder, Stevns Klint chalk and Dan reservoir chalk has previously been measured by the BET method by Hao et al. (2020) to be $0.34,2.21$, and $2.70 \mathrm{~m}^{2} / \mathrm{g}$, respectively [48].

\subsection{Core Preparation and Water Flooding}

Each core plug was cleaned and dried before use. Reservoir core plugs were cleaned by a flow-through method in which methanol and toluene were injected cyclically at $40{ }^{\circ} \mathrm{C}$ through the core plug. Outcrop samples, which were too brittle for flow-through cleaning, were cleaned using a Soxhlet apparatus just with methanol solvent as the samples had not been in contact with oil. After cleaning, core plugs were dried at $70^{\circ} \mathrm{C}$ in an oven until no further changes in core plug weight were observed.

Ageing of the saturated core plug is necessary to condition the rock surface with the surface-active constituents in the crude oil. Ageing can be carried out by incubating the saturated core for a period to allow the fluids and surfaces to equilibrate, or by extending the drainage process by injecting multiple pore volumes of crude oil to achieve equilibrium. Both methods have been shown to change the wettability of carbonate rocks from water-wet to a mixed-wet state $[42,49]$; however dynamic ageing can be more effective in restoring 
the initial wettability of the core in shorter time [41]. In the dynamic approach in this study, 15-20 pore volumes of crude oil were injected through the core plug at two flow rates of 0.1 and $0.5 \mathrm{~mL} / \mathrm{min}$. Effluent oil polar compounds, specifically carbonyl-containing compounds, were observed to stabilize in concentration during this injection period. The core plug was then incubated for 2-3 days at reservoir conditions to allow for rock-fluid equilibration before brine injection studies.

The core flooding rig, including cylinders for injection of different brines and oil, a Hassler core holder, and a back pressure regulator, was mounted in a $67 \mathrm{~cm} \times 54 \mathrm{~cm}$ oven (Figure 3). Pressure, temperature, and flow rate data were recorded in a LabVIEW ${ }^{\circledR}$, National Instruments, Texas, USA program. A differential pressure $(\Delta \mathrm{P})$ transducer was installed to measure the pressure difference across the core plug. This transducer has a range of \pm 15 bar with an accuracy of $\pm 0.5 \%$ full scale. All experiments were conducted at a temperature of $70{ }^{\circ} \mathrm{C}$ and a pressure of 170 bar to mimic reservoir conditions in the Danish Southern North Sea oil reservoirs, from where the core material originates.

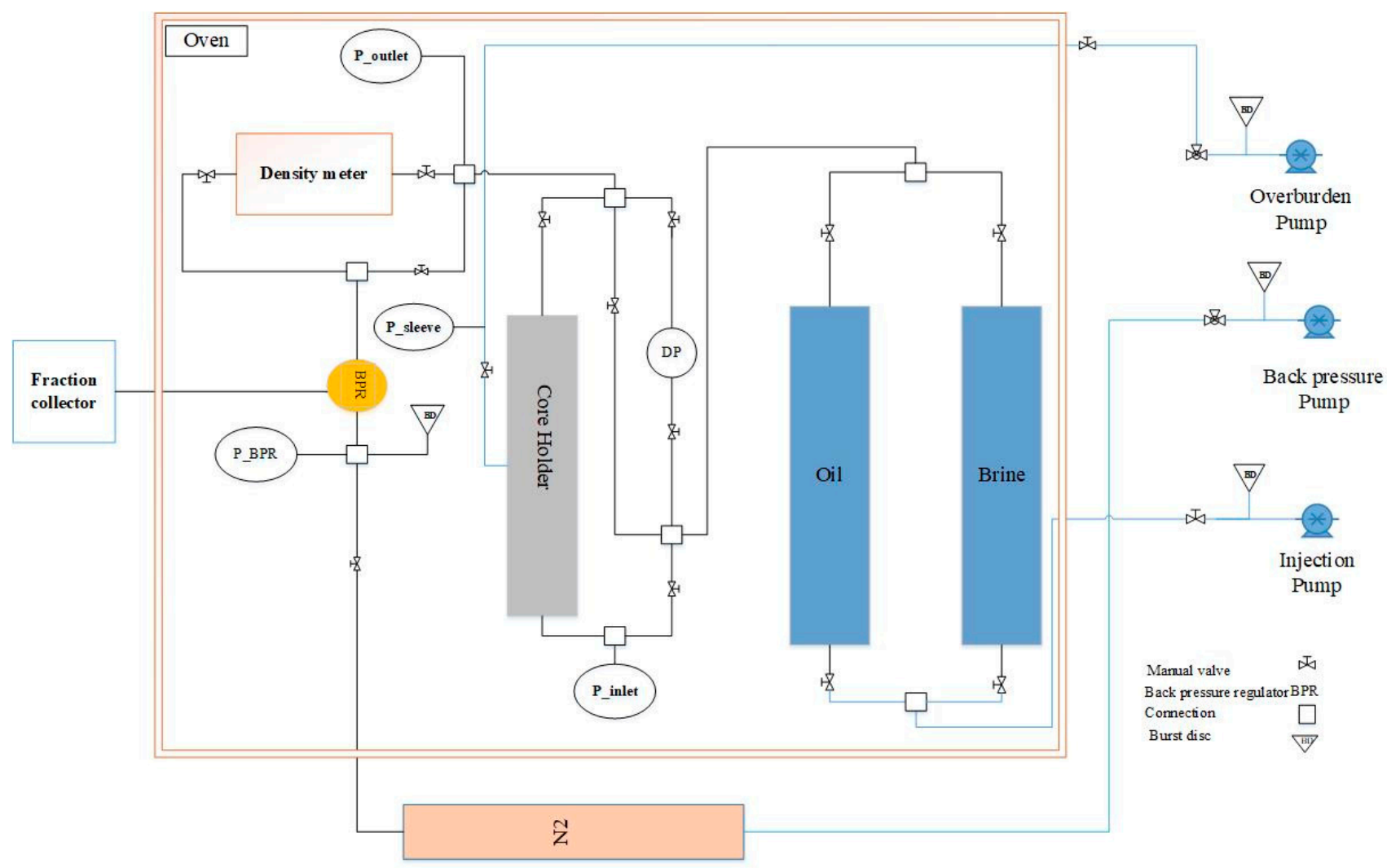

Figure 3. Schematic of core flooding apparatus used in the study. The equipment mounted in the oven (the orange line) to be kept at reservoir temperature.

A fraction collector was employed to collect the effluents. Effluents were collected in cuvettes readable by a multi-wavelength separation analyzer (LUMiReader ${ }^{\circledR}, \mathrm{LUM}^{\mathrm{TM}}$ $\mathrm{GmbH}$, Germany) instrument in order to accurately measure the volumes of oil produced. This measurement technique allows for the detection of oil in the effluent with volumes in the 3-2500 $\mu \mathrm{L}$ range [50]. After saturating the core plugs with formation water, crude oil was injected into the core to establish initial water saturation $\left(S_{w i}\right)$. The $S_{w i}$ was calculated by material balance based on the produced water and the core pore volume. The flow direction was kept the same throughout each study, including flow-through cleaning, drainage process, and water flooding stages.

Green and Willhithe [51] reported that, at capillary numbers $\left(\mathrm{N}_{\mathrm{c}}\right)$ less than $10^{-6}$, the residual oil saturation $\left(\mathrm{S}_{\mathrm{or}}\right)$ is relatively constant and not a function of the magnitude of 
$\mathrm{N}_{\mathrm{c}}$. In this study, the injection rates were chosen to maintain experiments in the capillary dominant region (i.e., $\mathrm{N}_{\mathrm{c}}<10^{-6}$ ).

Table 4 presents a summary of the brine injection scenarios investigated in this work. These studies can be broadly divided into three groups based on the core material employed:

(1) Stevns Klint (outcrop) chalk samples (Experiment 1, 2, and 3). We used a model oil with and without the presence of acid to evaluate the effectiveness of the timeline of the dynamic ageing method and its effect on the core wettability.

(2) Reservoir rocks from the Ekofisk formation (Experiment 4, 5, and 6). We used a dead reservoir crude oil to evaluate the optimum stage of low salinity injection on oil recovery.

(3) Reservoir rock from the Tor formation (Experiment 7, 8, and 9). Similar to the previous step, a dead reservoir crude oil was used. Injection scenarios were designed to complement those previously investigated on the rocks from the Ekofisk formation in the secondary and tertiary stage of flooding.

Table 4. Injection sequences and scenarios of core flooding experiments.

\begin{tabular}{|c|c|c|}
\hline Core Material & Experiment & Injection Scenario \\
\hline \multirow{3}{*}{ Stvens Klint } & 1 & $\mathrm{FW} \rightarrow \mathrm{SW} \rightarrow \mathrm{DSW}(1 / 10)$ \\
\hline & 2 & $\mathrm{FW} \rightarrow \mathrm{SW} \rightarrow \mathrm{DSW}(1 / 5) \rightarrow \mathrm{DSW}(1 / 10) \rightarrow \mathrm{DSW}(1 / 20)$ \\
\hline & 3 & $\mathrm{FW} \rightarrow \mathrm{SW} \rightarrow \mathrm{DSW}(1 / 5) \rightarrow \mathrm{DSW}(1 / 10) \rightarrow \mathrm{DSW}(1 / 20)$ \\
\hline \multirow{3}{*}{ Dan-Ekofisk } & 4 & $\mathrm{FW} \rightarrow \mathrm{SW} \rightarrow \mathrm{DSW}(1 / 5) \rightarrow \mathrm{DSW}(1 / 10) \rightarrow \mathrm{DSW}(1 / 20)$ \\
\hline & 5 & $\mathrm{SW} \rightarrow \mathrm{DSW}(1 / 10) \rightarrow \mathrm{DSW}(1 / 10)+2 \mathrm{~S} \rightarrow \mathrm{DSW}(1 / 10)+2 \mathrm{~S}+4 \mathrm{Mg}$ \\
\hline & 6 & $\begin{array}{c}\text { DSW }(1 / 10) \rightarrow \text { DSW (1/10) } 500 \mathrm{ppm} \mathrm{NO}_{3} \rightarrow \text { SW } \rightarrow \text { DSW }(1 / 10) 500 \mathrm{ppm} \\
\mathrm{NO}_{3} \rightarrow \text { FW }\end{array}$ \\
\hline \multirow{3}{*}{ Dan-Tor } & 7 & $\mathrm{SW} \rightarrow \mathrm{DSW}(1 / 10)$ \\
\hline & 8 & DSW $(1 / 10) \rightarrow$ FW \\
\hline & 9 & $\mathrm{FW} \rightarrow \mathrm{DSW}(1 / 10)$ \\
\hline
\end{tabular}

\subsection{Characterization Techniques}

\subsubsection{Effluent Analysis}

Effluent brine samples were analyzed using ion chromatography (IC). Before analysis, samples were filtered using a $0.2-\mu \mathrm{m}$ syringe filter and diluted in deionized water. A ThermoScientific ${ }^{\circledR}$ Dionex ICS-1100 IC, Thermo Fisher Scientific, USA setup equipped with a Dionex IonPac CS16-4 $\mu \mathrm{m}$ column was used. The eluent was an aqueous solution of 30-mM methanesulfonic acid (MSA). Each sample, placed in an auto-sampler, was run at least twice, and the mean values, within $\pm 3 \%$ uncertainty, were reported.

\subsubsection{CT Imaging of Core Plugs}

A core slice was imaged (a) with pore-fluids of air after drying the core; (b) with FW after saturation; and (c) after flooding with the combination of FW and oil. The images were acquired in the Core Plug Geometry Settings with a custom-built submicron CT scanner. The X-ray tube operated at a $90-\mathrm{kV}$ tube voltage and an $80-\mu \mathrm{A}$ tube current, with $\mathrm{a} \mathrm{LaB}_{6}$ cathode operating with a large focus size. A one-millimeter-thick copper filter was placed in front of the X-ray window to reduce beam hardening effects; other minor beam hardening effects were removed by filtration in the image processing and visualization stage. The exposure time was $4 \mathrm{~s}$ per frame, and 3 frames were averaged for each angle, 3600 angles for each sample. The reconstructed image had a resolution of $92 \mu \mathrm{m} /$ voxel. Octopus Reconstruction 8.9.4 reconstructed 3D images from projections. Image processing and visualization were performed by Avizo ${ }^{\mathrm{TM}}$ 9.5, Thermo Fisher Scientific, USA.

\section{Results and Discussion}

\subsection{Oil Effect}

Using Stevns Klint core samples, the role of the oil phase on the oil recovery results was investigated. In the first experiment, hexadecane was used as the hydrocarbon phase. 
In the second experiment, a stearic acid-hexadecane mixture was used to mimic the total oil acidity, and for the third experiment, reservoir crude oil was used.

The results of the first experiment are shown in Figure 4. This figure shows no increase in oil recovery with changing the injection brine from FW to SW, and SW to DSW. In addition, increasing the injection flow rate did not result in enhanced oil recovery. The lack of brine effect is expected as alkanes neither affect surface wettability alteration nor have strong fluid-fluid interactions $[15,52]$. In the second experiment (see Figure 5), a minor response was observed as brines changed from SW to DSW; this might suggest that the addition of stearic acid introduces a rock-fluid or fluid-fluid interaction which is sensitive to brine composition. Experiment 3, using crude oil, also showed a response to a decrease in brine salinity—especially from FW to SW (Figure 6).

Breakthrough times for these three experiments were similar, suggesting that the bulk viscous production was almost comparable as the same rock material was employed. However, comparing the oil production after breakthrough reveals information on the effect of surface wettability and the response of oil to various injected brine compositions. Experiment 1 shows a significantly lower production after breakthrough, followed by experiment 2, and the most oil production (after breakthrough) was observed for the third experiment, which indicates the role of components present in the crude oil in changing the surface wettability during the period of ageing and its effect on oil production during the waterflooding stage in the same rock material.

Standnes and Austad (2000) evaluated the effect of amount of acidic components of crude oil measured by the acid number (AN) on aging and the wettability alteration by spontaneous imbibition tests. They reported higher wettability alteration by increasing AN (mg KOH/g), which is mostly determined as carboxylic acids in crude oil $[15,53]$.

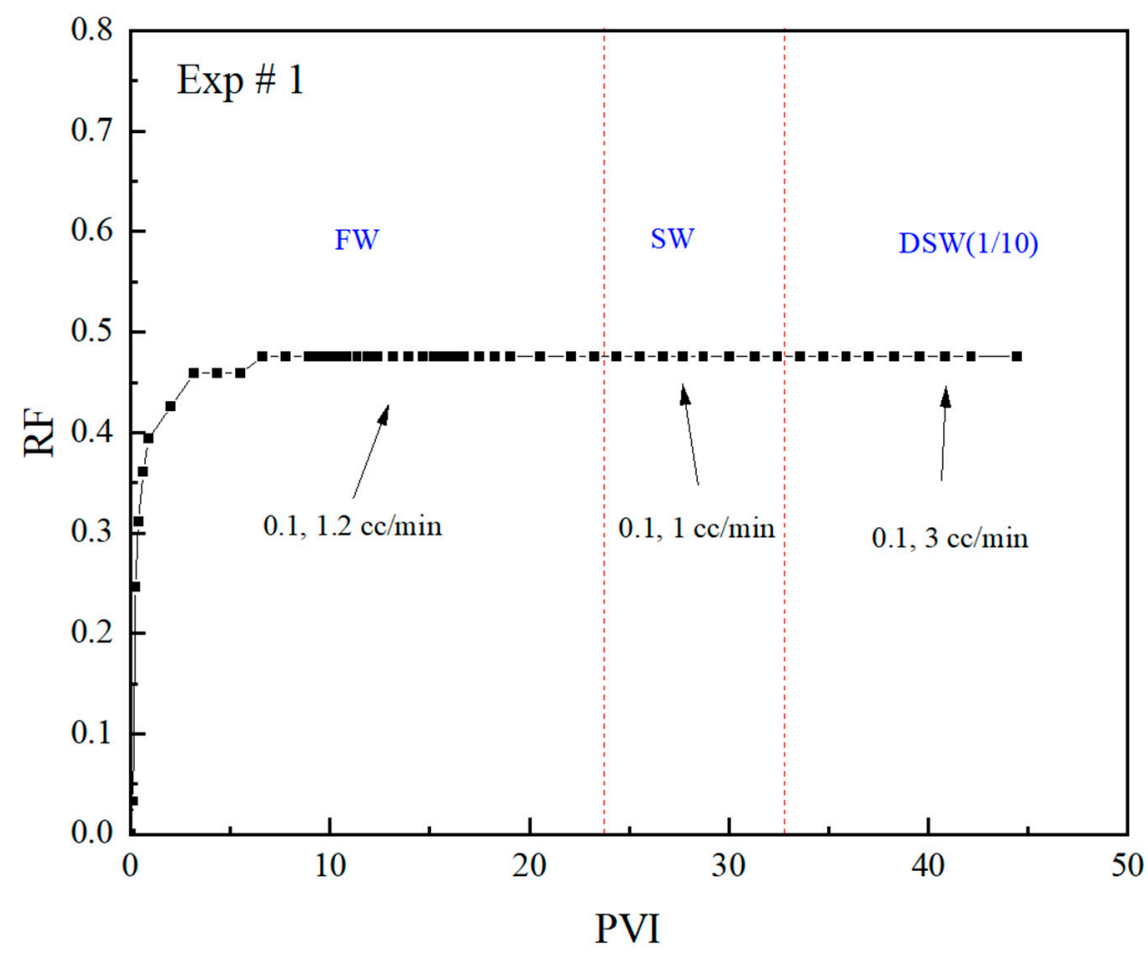

Figure 4. Oil recovery factors on outcrop chalk with hexadecane as the oil phase. 


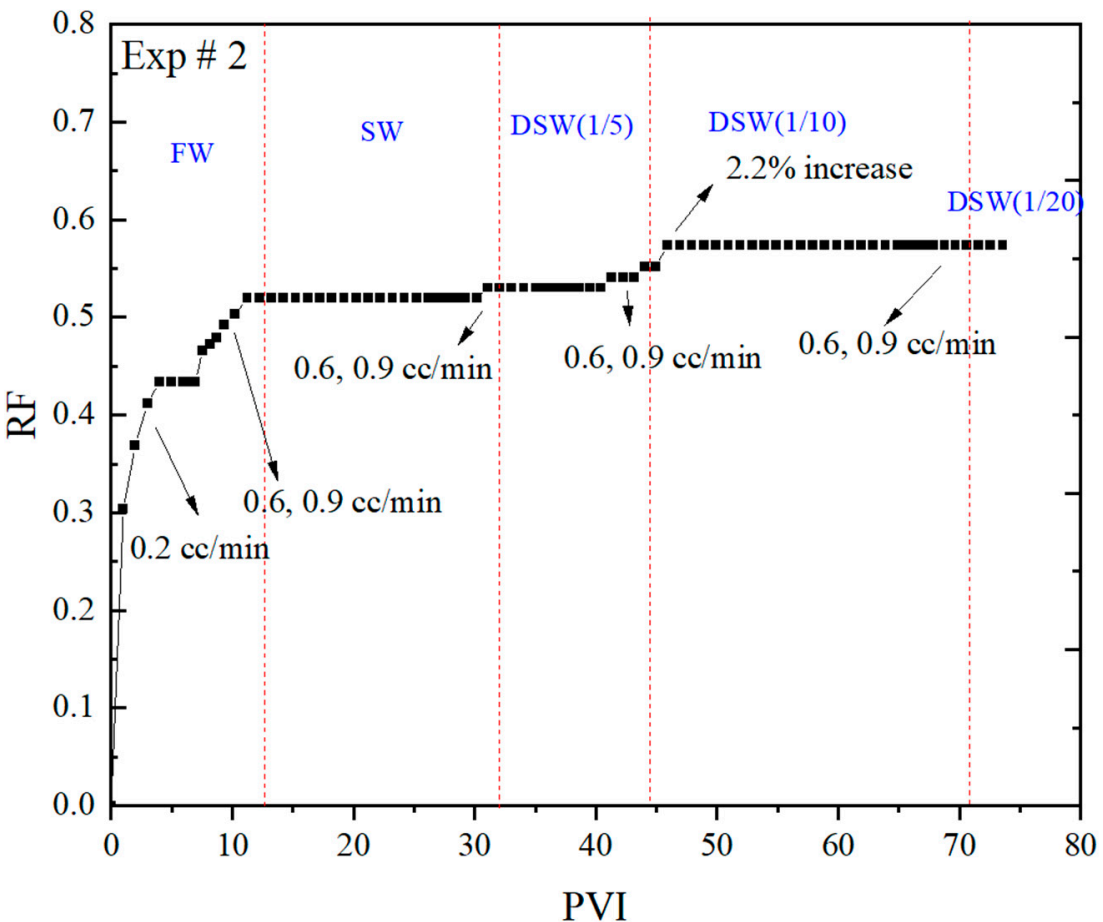

Figure 5. Oil recovery of experiment 2 adding stearic acid to hexadecane as the oil phase and Stevns Klint as the rock material. The flow rate starts with $0.2 \mathrm{~mL} / \mathrm{min}$ and increased to 0.6 and then to $0.9 \mathrm{~mL} / \mathrm{min}$ before changing each brine.

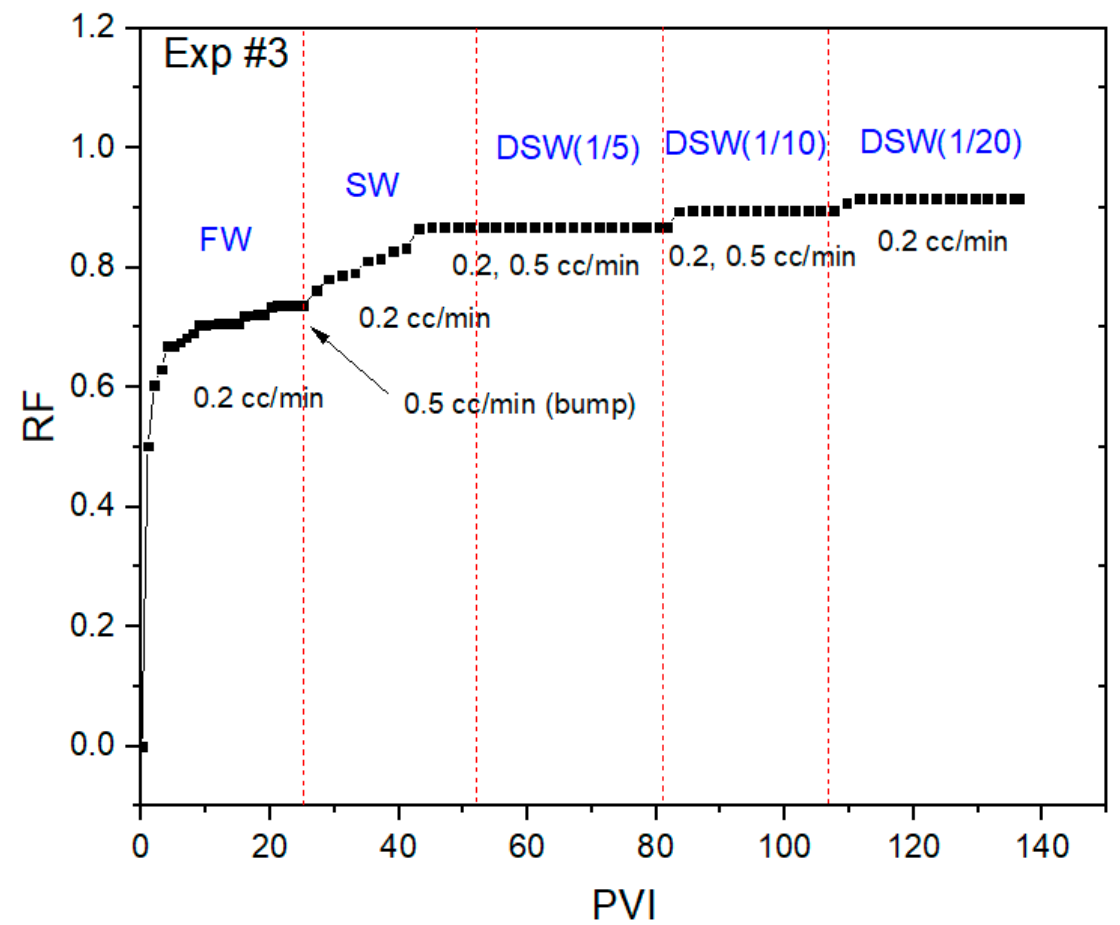

Figure 6. Oil recovery of experiment 3 using crude oil as the oil phase and Stevens Klint as the rock material. The flow rate starts with $0.2 \mathrm{~mL} / \mathrm{min}$ and increased to 0.6 and then to $0.9 \mathrm{~mL} / \mathrm{min}$ before changing each brine. 
Stearic acid was added to hexadecane in the second experiment to see the effect of presence of acids in the oil phase on aging and oil recovery. We compared the oil recovery from the two experiments with no acid in the oil phase (just hexadecane) and with presence of acid in the oil phase (stearic acid + hexadecane). We used crude oil in the subsequent experiments as the oil phase, because the model oil is not representative of the oil phase.

The importance of various polar groups in the oil phase plays a major role in the restoring the initial core wettability and further response of the system to brine injection scenarios.

\subsection{Brine Effect}

Experiments 4-9 were conducted on reservoir core plugs from two different wells; various injection scenarios were implemented to evaluate the effect of brine composition on oil recovery. The detailed recovery curves versus injection pore volume are reported in the supplementary file. In this section, we focus on the effect of brine composition on secondary and tertiary oil production. A summary of secondary and tertiary recovery factors for experiments $4-9$ is reported in Table 5.

Table 5. Different recovery factors at secondary and tertiary stages for experiments 4-9.

\begin{tabular}{|c|c|c|c|c|c|}
\hline Formation & Experiment & Secondary Brine & $\begin{array}{l}\text { RF } \\
(\% \text { IOIP) }\end{array}$ & Tertiary Brine & $\begin{array}{c}\text { EOR } \\
\text { (\%IOIP) }\end{array}$ \\
\hline \multirow{3}{*}{ Ekofisk } & 4 & FW & 59.2 & SW & 1.7 \\
\hline & 5 & SW & 49.8 & DSW $(1 / 10)$ & 4.9 \\
\hline & 6 & DSW $(1 / 10)$ & 59.1 & DSW $(1 / 10)+\mathrm{NO}_{3}{ }^{2-}$ & 0.0 \\
\hline \multirow{3}{*}{ Tor } & 7 & SW & 69.6 & DSW $(1 / 10)$ & 1.1 \\
\hline & 8 & DSW $(1 / 10)$ & 85.4 & FW & 7.3 \\
\hline & 9 & FW & 82.5 & DSW $(1 / 10)$ & 0.0 \\
\hline
\end{tabular}

\subsubsection{Secondary Water Flooding}

Figures 7 and 8 show the secondary and tertiary recovery factors obtained by injecting FW, SW, and DSW (1/10), using core plugs from the Ekofisk and Tor formations, respectively.

While the recovery factors for these two different rock materials are different, in both cases, DSW $(1 / 10)$ and FW are better candidates for enhanced oil production when compared to SW. This observation is in line with a recent study on reservoir chalk from Tor formation [54]. For core plugs from Ekofisk formation, both FW and DSW (1/10) showed more than $9 \%$ additional oil recovery compared to SW. The additional oil production when DSW $(1 / 10)$ and FW were injected was even higher (up to 15\%) for the core plug from the Tor formation. Differences in oil recovery factors can be attributed to differences in rock quality; this is further discussed in Section 3.3.

\subsubsection{Tertiary Water Flooding}

The tertiary oil production results also showed the potential of FW and DSW on improving oil recovery. In experiment 6 , DSW (1/10) spiked with 500 ppm of sodium nitrate was injected at the tertiary stage and no additional oil was recovered. Nitrate was added to diluted seawater just in one concentration to check the effect on oil recovery because it has shown positive effect on reducing souring in oil reservoirs [55]. Further, adding both sulfate and magnesium to DSW $(1 / 10)$ (experiment 5) showed no impact on oil production after the tertiary stage. According to the results from Seyyedi et al. (2018), increasing the concentration of sulfate in SW in flooding experiments on reservoir core plugs from Ekofisk formation did not have any effect on oil recovery after secondary flooding stage [35]. In the same study, stronger oil recovery potential was reported for LSWI in secondary stage of flooding in comparison to the tertiary stage. It should be noted that, other than salinity, the main difference between FW, SW, and DSW is the higher concentration of magnesium and sulfate in the SW compared to FW and DSW. This could be the reason why the injection of FW and DSW leads to higher oil recoveries, both at the 
secondary and tertiary stages. This hypothesis needs further investigation which is outside the scope of the current paper.
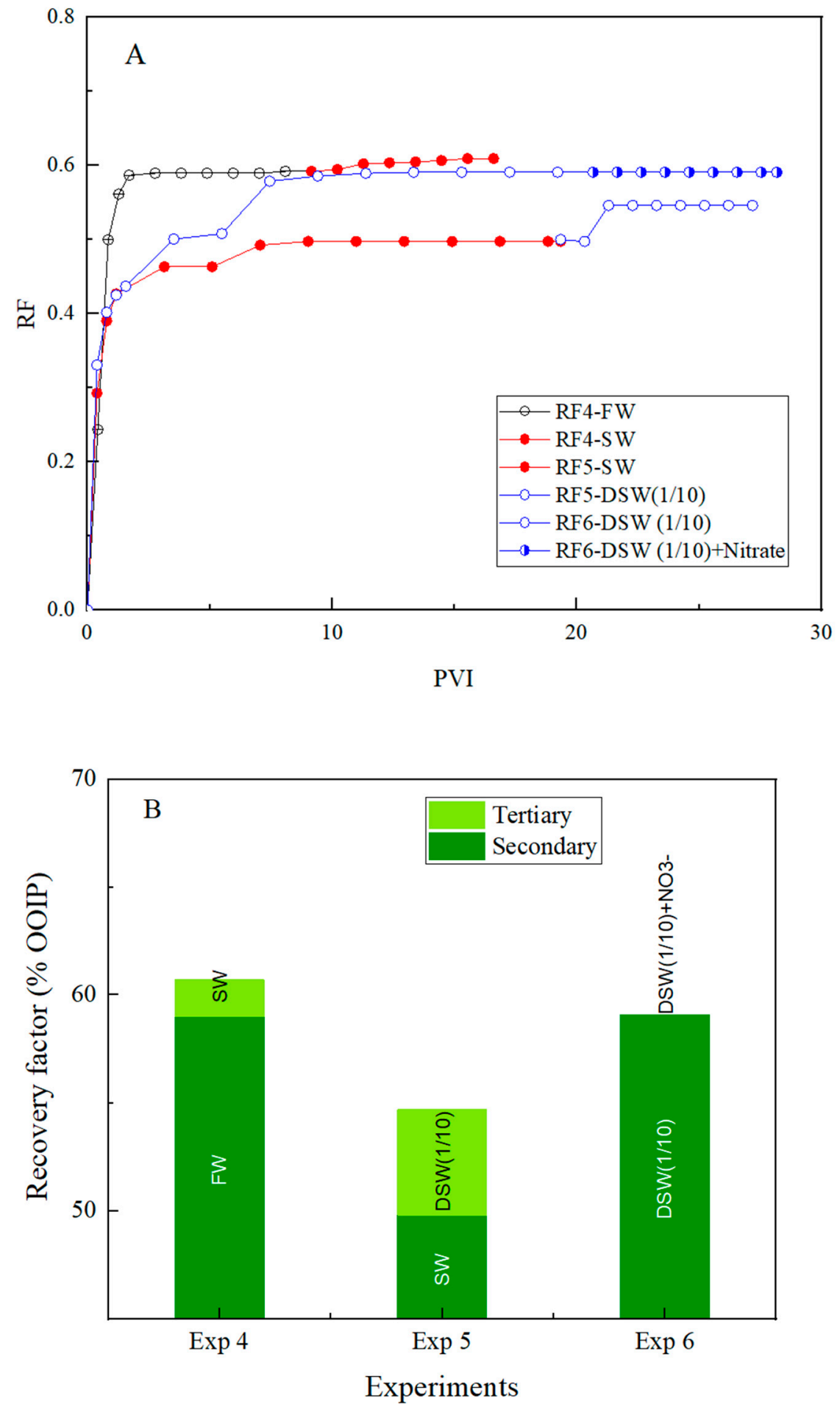

Figure 7. (A) Recovery factors for secondary and tertiary stages of flooding for experiments 4 to 6 on samples from Ekofisk formation. (B) Comparison of recovery factors as percentage of initial oil in place. Recovery factor curves versus injection pore volumes for all the flooding stages (after tertiary) are shown in supplementary file (Figure S1). 

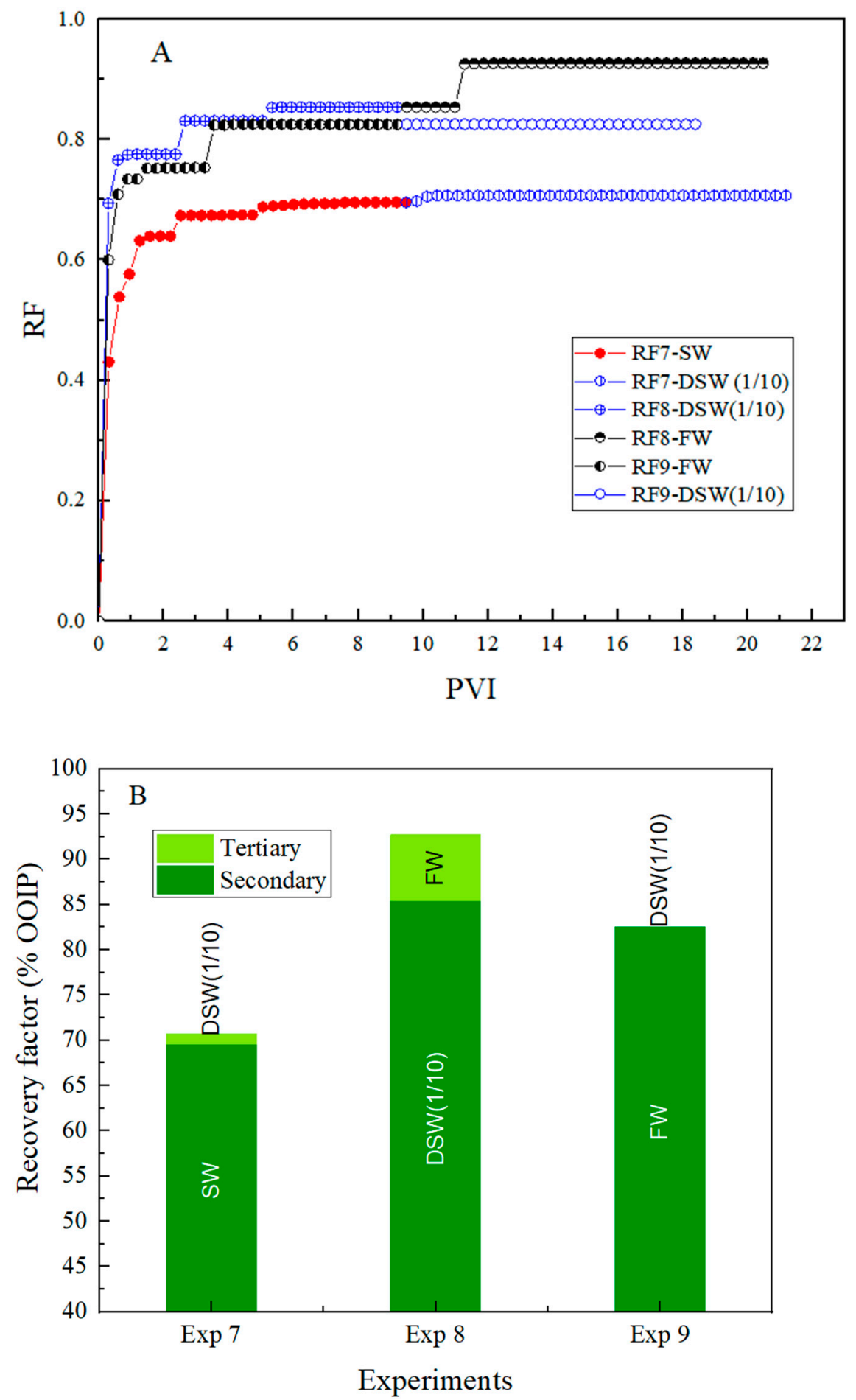

Figure 8. (A) Recovery factors for secondary and tertiary stages of flooding for experiments 7 to 9 on samples from Tor formation. (B) Comparison of recovery factors as percentage of initial oil in place.

At the end of experiment 6 , the core plug had incubation for approximately $17 \mathrm{~h}$ with DSW $(1 / 10)+\mathrm{NO}_{3}{ }^{2-}$ and $\mathrm{FW}$ in the pore space. In both brines, incubation led to an increase in oil recovery factors near to $1.2 \%$ OOIP. This suggests the impact of incubation independent of brine type (see Figure S1C in supplementary file).

Effluents from experiments 5 and 6 (the same core slice was used for both experiments) were analyzed for changes in ion compositions. Plots of ion concentrations as function of the injected pore volumes are included in the supplementary file (Figures S2-S4). In 
Table 6 , the differences between the injected brine and steady-state effluent concentrations for SW and DSW $(1 / 10)$ are presented.

Table 6. Deviations between injected brine and steady-states effluent concentrations.

\begin{tabular}{ccccccc}
\hline \multirow{2}{*}{ Brine } & \multicolumn{3}{c}{ Experiment 5 } & \multicolumn{3}{c}{ Experiment 6 } \\
\cline { 2 - 7 } & $\mathbf{N a}$ & $\mathbf{M g}$ & $\mathbf{C a}$ & $\mathbf{N a}$ & $\mathbf{M g}$ & $\mathbf{C a}$ \\
\hline $\mathrm{SW}$ & $1 \%$ & $-6 \%$ & $13 \%$ & $0 \%$ & $-1 \%$ & $11 \%$ \\
\hline $\mathrm{DSW}(1 / 10)$ & $7 \%$ & $-2 \%$ & $66 \%$ & $2 \%$ & $-5 \%$ & $94 \%$ \\
\hline
\end{tabular}

In both experiments, we observe significant increases, relative to the injected brine concentrations, in the effluent calcium concentrations; this is indicative of calcium carbonate dissolution [56]. We also observed a decrease in magnesium concentrations; these results are consistent with a recent core-flooding study on standard core plugs from Tor formation [54]. As shown in Table 6, these increases are higher with the injection of DSW $(1 / 10)$. In contrast, minor decreases in the effluent magnesium concentrations were observed. The increased production of calcium in the effluent brine and a corresponding decrease in magnesium during the flooding process can be attributed to the formation of Ca-Mg containing rock phases in carbonate rocks [57]. A similar trend was reported for sandstone core plugs [58].

\subsection{Rock Effect}

A previous imbibition study reported that Tor core plugs had higher oil recovery factors (40-60\%) when compared to those from the Ekofisk formations (15-25\%) [59]. Spontaneous imbibition results for Tor formation correlated well with porosity, while, for Ekofisk formation cores, it did not correlate with any known rock property. Since the pore structures of both formations were reported to be similar, the differences in wettability and oil recoveries were related to differences in surface chemistry [60]. Consistent with previous imbibition tests in the literature, we observed higher oil recoveries in cores from the Tor formation. However, we propose that these differences can be attributed to variations in rock quality. Flow zone indicator (FZI), introduced by Amaefule et al. [61], identifies the hydraulic flow units based on the Kozeny-Carman model, which considers rock quality and pore structure. The modified flow zone indicator (MFZI) takes initial water saturation into account and could be used as a representative for the rock effect in waterflooding experiments. This parameter can be calculated using the two equations below:

$$
\begin{gathered}
\mathrm{FZI}=\frac{0.0314 \sqrt{\frac{\mathrm{k}}{\varnothing_{\mathrm{e}}}}}{\frac{\varnothing_{\mathrm{e}}}{1-\varnothing_{\mathrm{e}}}} \\
\mathrm{MFZI}=\mathrm{FZI} \times \frac{\sqrt{1-\mathrm{S}_{\mathrm{wi}}}}{\left(1-\mathrm{S}_{\mathrm{wi}}\right)^{2}}
\end{gathered}
$$

where permeability $\mathrm{k}$ is in $\mathrm{mD}$; FZI and MFZI are in micron; and porosity $\left(\varnothing_{\mathrm{e}}\right)$ and initial water saturation $\left(\mathrm{S}_{\mathrm{wi}}\right)$ are fractions. Increasing both rock quality $(\mathrm{k} / \varnothing)$ and initial water saturation increases the MFZI, therefore we can expect that, by increasing MFZI, the recovery factor will increase. Figure 9 shows the relationship between MFZI and oil recovery factors (secondary stage) for experiments 4 to 9 -all experiments conducted using reservoir material. 


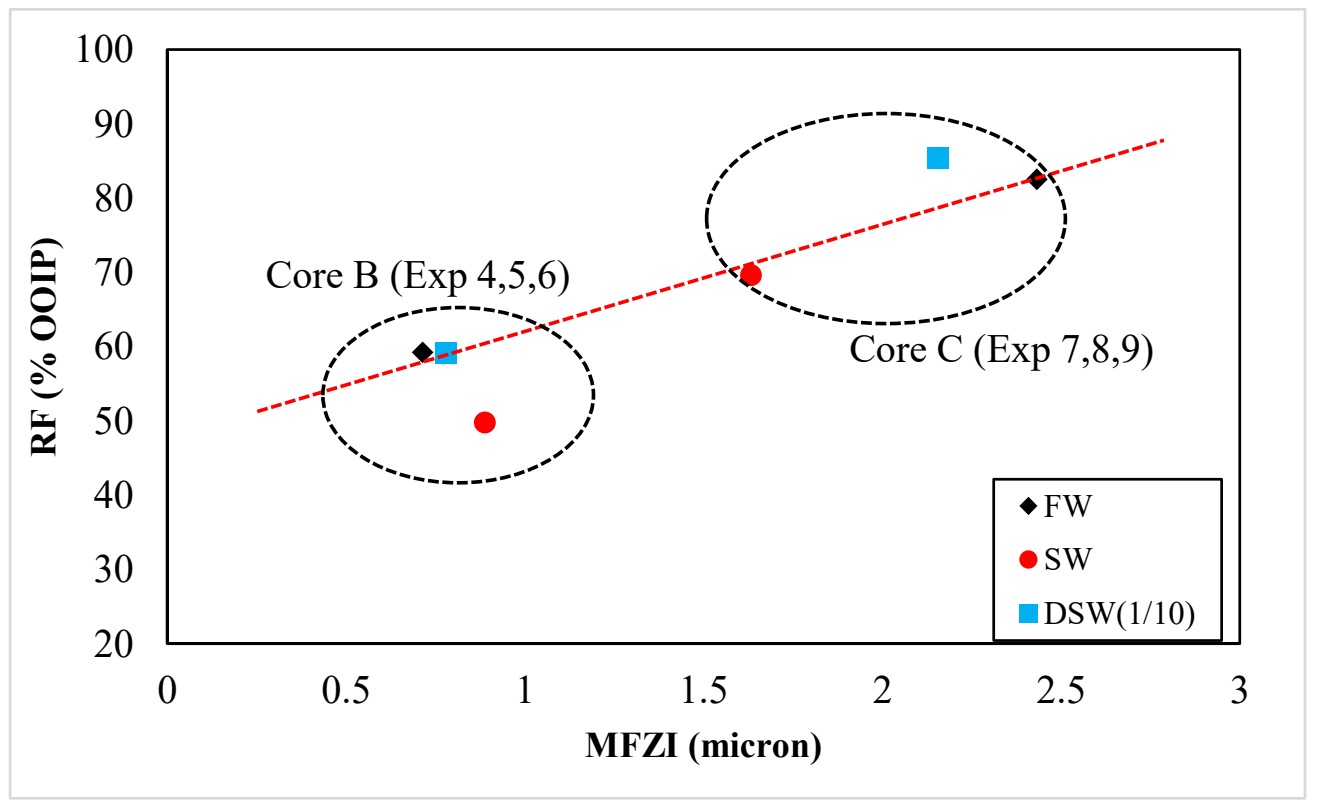

Figure 9. Correlation between MFZI and secondary recovery factor.

As shown in Figure 9, the oil recovery factors obtained from experiments on core $\mathrm{C}$ (Tor formation) have higher MFZI in comparison with core B (Ekofisk formation). Thus, core $\mathrm{C}$ from the Tor formation belongs to a different rock type than core $\mathrm{B}$ according to standard FZI-based rock type analysis [62,63]. This shows that higher MFZI can attribute in higher recovery factors for experiments on core plug C. It can be seen in this plot that the recovery factors for SW injection lie under the linear trend passing the recovery factors for FW, whereas the recovery factors for DSW lie above this trend line.

\subsection{Capillary End Effect}

In experiments 1-3, "bump" flooding was performed to evaluate the possible impact of capillary end effect on oil recovery. As shown in Figures 4-6, increasing the injection flow rate did not increase the production of oil, except for a minor effect in experiment 2 during the first DSW stage. These observations support the assumption that capillary end effects are not significant at the experimental conditions.

CT imaging of a core plug after a core flooding experiment was acquired to observe the fluid distribution. The FW and crude oil used to saturate the core and establish $\mathrm{S}_{\mathrm{wi}}$ were separately scanned and resulted in the following absorption coefficients, as shown in Table 7.

Table 7. Formation water and oil absorption coefficients and uncertainties.

\begin{tabular}{ccc}
\hline Fluid & Average X-ray Absorption Coefficient $\left.\mathbf{( c m}^{-\mathbf{1}}\right)$ & Uncertainty \\
\hline Formation water & 0.221 & 0.0045 \\
Crude oil & 0.176 & 0.0045 \\
\hline
\end{tabular}

A photo of the core slice after flooding is taken and 3D visualizations are prepared in reference to the geometry of the core in Figure 10. In this figure, photos of core slice (A, B), core material density variation (C), and fluid distribution (D) are shown. In part (E), fluid distribution superimposed on core density variation is shown. According to the results of FW and oil absorption coefficients, by increasing the X-ray absorption coefficient, water distribution will result from fluid distribution (oil and water), as shown in part (F). Figure 11 shows the core density variations superimposed on high-water-content regions of the core corresponding to higher X-ray absorption coefficients. It can be inferred from this photo that oil is not be only trapped at the edges of the core as the water distribution is 
not homogeneous and the water seems to be able to penetrate permeable parts of the pores even at the edges.

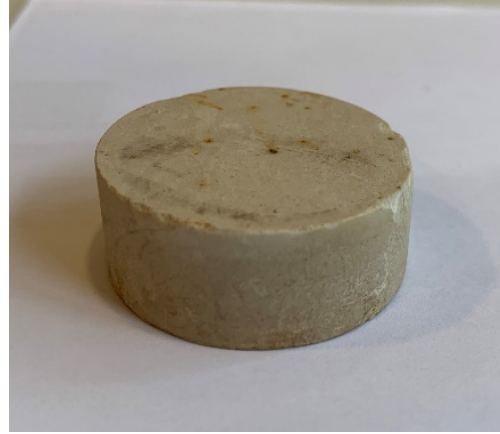

(A)

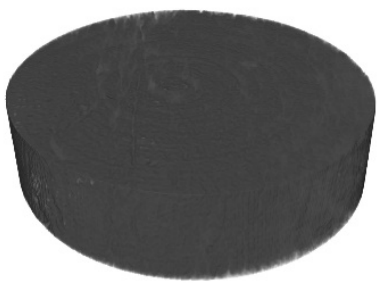

(D)

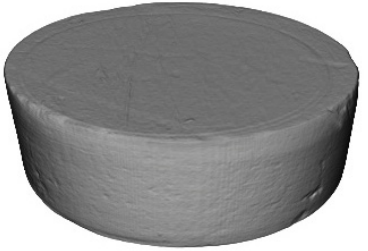

(B)

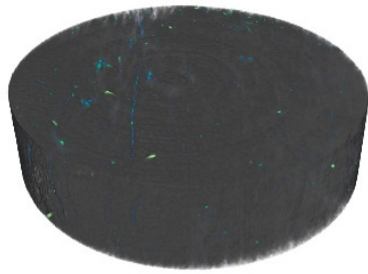

(E)

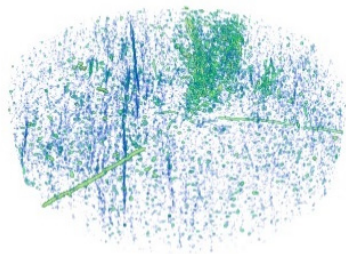

(C)

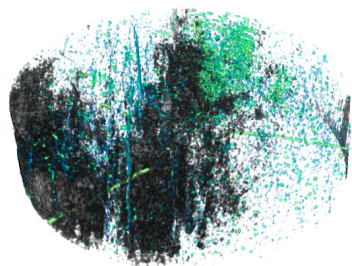

(F)

Figure 10. (A) photo of the core slice after flooding, (B) exterior of the core plug, (C) density variations, (D) qualitative fluid content, (E) fluid content superimposed on density variations, (F) fluid content that is highly likely to be the water phase.

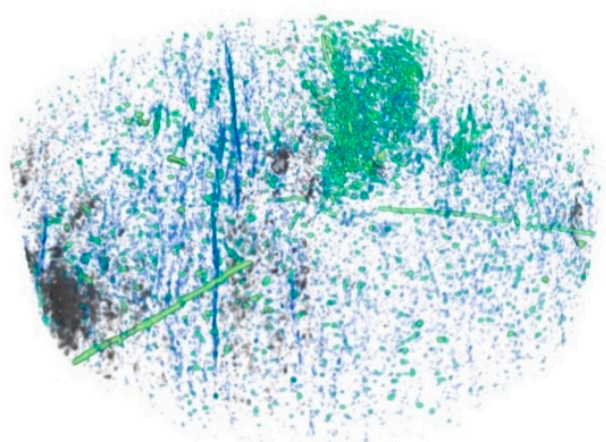

Figure 11. Fluid content that is highly likely to be the water phase superimposed on the density variations of the core plug (A video is provided in the Supplementary Materials).

\section{Conclusions}

In this study, chalk core samples, including outcrops and reservoir rocks, were used to investigate the effect of crude oil-brine-rock interactions during modified salinity water injection. We employed a reduced pore volume approach, together with a dynamic ageing protocol. The main outcomes of this study are:

(1) The presence of polar components in the oil phase has a significant effect on rock wettability during the ageing process. This subsequently affects the oil production during the water flooding stage. A significant difference was observed between a simple synthetic oil and reservoir crude oil, even when the total acid number was kept comparable. 
(2) At the secondary injection stage, ten-times-diluted seawater and formation water resulted in higher oil recovery than seawater. This was the case for core samples from both the Ekofisk and Tor formations.

(3) Consistent with the literature, Tor samples had higher oil recoveries when compared to Ekofisk core plugs. The modified flow zone indicator, a measure of rock quality, is likely the main variable responsible for the higher oil recoveries observed in Tor core samples.

(4) Bump flooding studies in Stevns Klint outcrops suggest that capillary end effects play a minor role. This effect, for the reservoir materials, with even lower permeabilities, would be much lower. In addition, CT images of a reservoir core after flooding show that capillary end effects are not significant even in these short core samples.

(5) Different oil recovery factors resulted from reservoir material and outcrop samples (experiment 4 and 3) show the importance of using reservoir core material in the experiments instead of outcrops.

The present study was carried out on a series of short core plugs and it is important to note the similar results obtained from longer core plugs reported in Mokhtari et al. (2021) for Tor formation [54]. In addition, the effects of pressure and temperature on these lowsalinity effects would be worth exploring in future work, as the present study is focused on the conditions for the chalk reservoirs in the Ekofisk and tor formations in the Danish North Sea. Further investigation on varying brine compositions would be of interest as studies of the surface and alterations occurring during flooding.

Supplementary Materials: The following are available online at https://www.mdpi.com/article/ 10.3390/en14175360/s1, Figure S1: Recovery factor curves at difference stages of flooding versus injection pore volumes for (A) Exp 4, (B) Exp 5, and (C) Exp 6. Figure S2: Effluent sodium concentration in Exp 5 (top) and Exp 6 (bottom). Recovery factor of the experiment is shown in circles. Figure S3: Effluent magnesium concentration in Exp 5 (top) and Exp 6 (bottom). Recovery factor of the experiment is shown in circles. Figure S4: Effluent calcium concentration relates to Exp 5 (top) and $\operatorname{Exp} 6$ (bottom). Recovery factor of the experiment is shown in circles.

Author Contributions: Conceptualization, K.L.F.; Formal analysis, S.M., B.U.A., A.A. and R.M.; Investigation, S.M., B.U.A. and A.A.; Methodology, S.M., A.A., R.M. and K.L.F.; Supervision, K.L.F.; Validation, R.M.; Writing—original draft, S.M.; Writing—review \& editing, B.U.A., A.A., R.M. and K.L.F. All authors have read and agreed to the published version of the manuscript.

Funding: This research received no external funding.

Institutional Review Board Statement: Not applicable.

Informed Consent Statement: Not applicable.

Data Availability Statement: Not applicable.

Acknowledgments: This research has received funding from the Danish Hydrocarbon Research and Technology Centre (DHRTC). The authors would like to acknowledge the Danish Underground Consortium (Total, Noreco, and Nordsøfonden).

Conflicts of Interest: The authors declare no conflict of interest.

\section{References}

1. Tang, G.Q.; Morrow, N.R. Influence of Brine Composition and Fines Migration on Crude/Oil/Rock Interactions and Oil Recovery. J. Pet. Sci. Eng. 1999, 24, 99-111. [CrossRef]

2. Aghaeifar, Z.; Strand, S.; Austad, T.; Puntervold, T.; Aksulu, H.; Navratil, K.; Storås, S.; Håmsø, D. Influence of Formation Water Salinity/Composition on the Low-Salinity Enhanced Oil Recovery Effect in High-Temperature Sandstone Reservoirs. Energy Fuels 2015, 29, 4747-4754. [CrossRef]

3. Jackson, M.D.; Vinogradov, J.; Hamon, G.; Chamerois, M. Evidence, mechanisms and improved understanding of controlled salinity waterflooding part 1: Sandstones. Fuel 2016, 185, 772-793. [CrossRef]

4. Mamonov, A.; Kvandal, O.A.; Strand, S.; Puntervold, T. Adsorption of polar organic components onto sandstone rock minerals and its effect on wettability and enhanced oil recovery potential by smart water. Energy Fuels 2019, 33, 5954-5960. [CrossRef] 
5. Mamonov, A.; Puntervold, T.; Strand, S.; Hetland, B.; Andersen, Y.; Wealth, A.; Nadeau, P.H. Contribution of Feldspar Minerals to $\mathrm{pH}$ during Smart Water EOR Processes in Sandstones. Energy Fuels 2020, 34, 55-64. [CrossRef]

6. Mohammadkhani, S.; Shahverdi, H.; Esfahany, M.N. Impact of salinity and connate water on low salinity water injection in secondary and tertiary stages for enhanced oil recovery in carbonate oil reservoirs. J. Geophys. Eng. 2018, 15, 1242-1254. [CrossRef]

7. Zaeri, M.R.; Hashemi, R.; Shahverdi, H.; Sadeghi, M. Enhanced oil recovery from carbonate reservoirs by spontaneous imbibition of low salinity water. Pet. Sci. 2018, 15, 564-576. [CrossRef]

8. Derkani, M.H.; Fletcher, A.; Abdallah, W.; Sauerer, B.; Anderson, J.; Zhang, Z. Low Salinity Waterflooding in Carbonate Reservoirs: Review of Interfacial Mechanisms. Colloids Interfaces. 2018, 2, 20. [CrossRef]

9. Strand, S.; Høgnesen, E.J.; Austad, T. Wettability alteration of carbonates-Effects of potential determining ions (Ca2+and SO42-) and temperature. Colloids Surf. A Physicochem. Eng. Asp. 2006, 275, 1-10. [CrossRef]

10. Karoussi, O.; Hamouda, A.A. Imbibition of sulfate and magnesium ions into carbonate rocks at elevated temperatures and their influence on wettability alteration and oil recovery. Energy Fuels. 2007, 21, 2138-2146. [CrossRef]

11. Standnes, D.C.; Austad, T. Wettability alteration in chalk 2. Mechanisms for wettability alteration from oil-wet to water-wet using surfactants. J. Pet. Sci. Eng. 2000, 28, 123-143. [CrossRef]

12. Austad, T.; Shariatpanahi, S.F.; Strand, S.; Black, C.J.J.; Webb, K.J. Conditions for a low-salinity Enhanced Oil Recovery (EOR) effect in carbonate oil reservoirs. Energy Fuels. 2012, 26, 569-575. [CrossRef]

13. Hamouda, A.A.; Maevskiy, E. Oil recovery mechanism(s) by low salinity brines and their interaction with chalk. Energy Fuels 2014, 28, 6860-6868. [CrossRef]

14. Zahid, A.; Sandersen, S.B.; Stenby, E.H.; von Solms, N.; Shapiro, A. Advanced waterflooding in chalk reservoirs: Understanding of underlying mechanisms. Colloids Surf. A Physicochem. Eng. Asp. 2011, 389, 281-290. [CrossRef]

15. Austad, T. Water-Based EOR in Carbonates and Sandstones: New Chemical Understanding of the EOR Potential Using "Smart Water". In Enhanced Oil Recovery Field Case Studies; Elsevier: Amsterdam, The Netherlands, 2013. [CrossRef]

16. Al Shalabi, E.W.; Sepehrrnoori, K.; Delshad, M. Mechanisms behind low salinity water injection in carbonate reservoirs. Fuel 2014, 121, 11-19. [CrossRef]

17. Zhang, P.; Tweheyo, M.T.; Austad, T. Wettability alteration and improved oil recovery by spontaneous imbibition of seawater into chalk: Impact of the potential determining ions $\mathrm{Ca}^{2+}, \mathrm{Mg}^{2+}$, and $\mathrm{SO}^{42-}$. Colloids Surf. Physicochem. Eng. Asp. 2007, 301, 199-208. [CrossRef]

18. Mahani, H.; Keya, A.L.; Berg, S.; Bartels, W.B.; Nasralla, R.; Rossen, W.R. Insights into the mechanism of wettability alteration by low-salinity flooding (LSF) in carbonates. Energy Fuels 2015, 29, 1352-1367. [CrossRef]

19. Alameri, W.; Teklu, T.W.; Graves, R.M.; Kazemi, H.; AlSumaiti, A.M. Wettability alteration during low-salinity water-flooding in carbonate reservoir cores. In Proceedings of the SPE Asia Pacific Oil Gas Conference Exhibition, Adelaide, Australia, 14-18 October 2014; pp. 1199-1216. [CrossRef]

20. Hiorth, A.; Cathles, L.M.; Madland, M.V. The Impact of Pore Water Chemistry on Carbonate Surface Charge and Oil Wettability. Transp. Porous Media 2010, 85, 1-21. [CrossRef]

21. Al-Sarihi, A.; Russell, T.; Bedrikovetsky, P.; Zeinijahromi, A. Fines Stabilization by Ca Ions and Its Effect on LSW Injection. Energy Fuels 2019, 33, 10775-10786. [CrossRef]

22. Al-Sarihi, A.; Zeinijahromi, A.; Genolet, L.; Behr, A.; Kowollik, P.; Bedrikovetsky, P. Effects of Fines Migration on Residual Oil during Low-Salinity Waterflooding. Energy Fuels 2018, 32, 8296-8309. [CrossRef]

23. Mohammadkhani, S.; Shahverdi, H.; Nielsen, S.M.; Esfahany, M.N.; Shapiro, A. Bicarbonate flooding of homogeneous and heterogeneous cores from a carbonaceous petroleum reservoir. J. Pet. Sci. Eng. 2019, 178, 251-261. [CrossRef]

24. Mokhtari, R.; Ayatollahi, S. Dissociation of polar oil components in low salinity water and its impact on crude oil-brine interfacial interactions and physical properties. Pet. Sci. 2019, 16, 328-343. [CrossRef]

25. Mokhtari, R.; Ayatollahi, S.; Fatemi, M. Experimental investigation of the influence of fluid-fluid interactions on oil recovery during low salinity water flooding. J. Pet. Sci. Eng. 2019, 106194. [CrossRef]

26. Chávez-Miyauchi, T.E.; Firoozabadi, A.; Fuller, G.G. Nonmonotonic Elasticity of the Crude Oil-Brine Interface in Relation to Improved Oil Recovery. Langmuir 2016, 32, 2192-2198. [CrossRef] [PubMed]

27. Mohammadkhani, S.; Shahverdi, H.; Kling, K.I.; Feilberg, K.L.; Esfahany, M.N. Characterization of interfacial interactions and emulsification properties of bicarbonate solutions and crude oil and the effects of temperature and pressure. J. Mol. Liq. 2020, 305, 112729. [CrossRef]

28. Wang, T.; Andersen, S.I.; Shapiro, A. Coalescence of oil droplets in microchannels under brine flow. Colloids Surf. A Physicochem. Eng. Asp. 2020, 598, 124864. [CrossRef]

29. Dang, C.; Nghiem, L.; Nguyen, N.; Chen, Z.; Nguyen, Q. Evaluation of CO2 Low Salinity Water-Alternating-Gas for enhanced oil recovery. J. Nat. Gas Sci. Eng. 2016, 35, 237-258. [CrossRef]

30. Shiran, B.S.; Skauge, A. Enhanced oil recovery (EOR) by combined low salinity water/polymer flooding. Energy Fuels 2013, 27, 1223-1235. [CrossRef]

31. Shaddel, S.; Tabatabae-Nejad, S.A. Alkali/Surfactant Improved Low-Salinity Waterflooding. Transp. Porous Media. 2015, 106, 621-642. [CrossRef]

32. Austad, T.; Standnes, D.C. Spontaneous imbibition of water into oil-wet carbonates. J. Pet. Sci. Eng. 2003, 39, 363-376. [CrossRef] 
33. Al-Attar, H.H.; Mahmoud, M.Y.; Zekri, A.Y.; Almehaideb, R.; Ghannam, M. Low-salinity flooding in a selected carbonate reservoir: Experimental approach. J. Pet. Explor. Prod. Technol. 2013, 3, 139-149. [CrossRef]

34. Goolsby, J.L.; Anderson, R.C. Pilot Water Flooding in a Dolomite Reservoir, The McElroy Field. J. Pet. Technol. 1964, 16, 1345-1350. [CrossRef]

35. Seyyedi, M.; Tagliaferri, S.; Abatzis, J.; Nielsen, S.M. An integrated experimental approach to quantify the oil recovery potential of seawater and low-salinity seawater injection in North Sea chalk oil reservoirs. Fuel 2018, 232, 267-278. [CrossRef]

36. Hao, J.; Mohammadkhani, S.; Shahverdi, H.; Esfahany, M.N.; Shapiro, A. Mechanisms of smart waterflooding in carbonate oil reservoirs-A review. J. Pet. Sci. Eng. 2019, 179, 276-291. [CrossRef]

37. Bartels, W.B.; Mahani, H.; Berg, S.; Hassanizadeh, S.M. Literature review of low salinity waterflooding from a length and time scale perspective. Fuel. 2019, 236, 338-353. [CrossRef]

38. Shehata, A.M.; Alotaibi, M.B.; Nasr-El-Din, H.A. Waterflooding in Carbonate Reservoirs: Does the Salinity Matter? SPE Reserv. Eval. Eng. 2014, 17, 304-313. [CrossRef]

39. Jones, S.A.; van der Bent, V.; Farajzadeh, R.; Rossen, W.R.; Vincent-Bonnieu, S. Small Core Flood Experiments for Foam EOR Screening Surfactant Applications. In Proceedings of the 18th European symposium on Oil Recovery, Dresden, Germany, 14-16 April 2015. [CrossRef]

40. Ahkami, M.; Chakravarty, K.H.; Xiarchos, I.; Thomsen, K.; Fosbøl, P.L. Determining Optimum Aging Time Using Novel Core Flooding Equipment. In Proceedings of the SPE Bergen One Day Seminar, Bergen, Norway, 20 April 2016.

41. Fernø, M.A.; Torsvik, M.; Haugland, S.; Graue, A. Dynamic laboratory wettability alteration. Energy Fuels. 2010, $24,3950-3958$. [CrossRef]

42. Graue, A.; Aspenes, E.; Bogno, T.; Moe, R.W.; Ramsdal, J. Alteration of wettability and wettability heterogeneity. J. Pet. Sci. Eng. 2002, 33, 3-17. [CrossRef]

43. Gomari, K.A.R.; Hamouda, A.A. Effect of fatty acids, water composition and $\mathrm{pH}$ on the wettability alteration of calcite surface. J. Pet. Sci. Eng. 2006, 50, 140-150. [CrossRef]

44. Yousef, A.A.; Al-Saleh, S.; Al-Kaabi, A.; Al-Jawfi, M. Laboratory investigation of the impact of injection-water salinity and ionic content on oil recovery from carbonate reservoirs. SPE Reserv. Eval. Eng. 2011, 14, 578-593. [CrossRef]

45. Blinkenberg, K.H.; Anderskouv, K.; Sheldon, E.; Bjerrum, C.J.; Stemmerik, L. Stratigraphically controlled silicification in Danian chalk and its implications for reservoir properties, southern Danish Central Graben. Mar. Pet. Geol. 2020, 115, 104134. [CrossRef]

46. Fabricius, I.L. Chalk: Composition, diagenesis and physical properties. Bull. Geol. Soc. Den. 2007, 55, 97-128. [CrossRef]

47. Røgen, B.; Fabricius, I.L. Influence of clay and silica on permeability and capillary entry pressure of chalk reservoirs in the North Sea. Pet. Geo. 2002, 8, 287-293. [CrossRef]

48. Hao, J.; Feilberg, K.L.; Shapiro, A. Kinetics of Calcite Dissolution and Ca-Mg Ion Exchange on the Surfaces of North Sea Chalk Powders. ACS Omega 2020, 5, 17506-17520. [CrossRef]

49. Sylte, J.E.; Thomas, L.K.; Rhett, D.W.; Bruning, D.D.; Nagel, N.B. Water Induced Compaction in the Ekofisk Field. In Proceedings of the SPE Annual Techical Conference Exhibition, Houston, TX, USA, 3-6 October 1999. [CrossRef]

50. Rendel, P.M.; Mohammadkhani, S.; Jensen, A.E.; Feilberg, K.L. An innovative method for the quantification of small amounts of crude oil in water using a multi-wavelength separation analyzer. J. Pet. Sci. Eng. 2021, 200, 108388. [CrossRef]

51. Green, D.W.; Willhite, G.P. Enhanced Oil Recovery; SPE Textbook Series Vol6; Society of Petroleum Engineers: Richardson, TX, USA, 1998.

52. Zhang, P.; Austad, T. The Relative Effects of Acid Number and Temperature on Chalk Wettability. In Proceedings of the SPE International Symposium Oilfield Chememistry, The Woodlands, TX, USA, 2-4 February 2005; pp. 3-9. [CrossRef]

53. Standnes, D.C.; Austad, T. Wettability alteration in chalk 1. Preparation of core material and oil properties. J. Pet. Sci. Eng. 2000, 28, 111-121. [CrossRef]

54. Mokhtari, R.; Anabaraonye, B.U.; Afrough, A.; Mohammadkhani, S.; Feilberg, K.L. Experimental investigation of low salinity water-flooding in tight chalk oil reservoirs. J. Pet. Sci. Eng. 2021, 109282. [CrossRef]

55. Hubert, C.; Voordouw, G. Oil Field Souring Control by Nitrate-Reducing Sulfurospirillum spp. Appl. Environ. Microbiol. 2007, 73, 2644-2652. [CrossRef] [PubMed]

56. Anabaraonye, B.U.; Crawshaw, J.P.; Trusler, J.P.M. Brine chemistry effects in calcite dissolution kinetics at reservoir conditions. Chem. Geol. 2019, 509, 92-102. [CrossRef]

57. Madland, M.V.; Hiorth, A.; Omdal, E.; Megawati, M.; Hildebrand-Habel, T.; Korsnes, R.I.; Evje, S.; Cathles, L.M. Chemical Alterations Induced by Rock-Fluid Interactions When Injecting Brines in High Porosity Chalks. Transp. Porous Media. 2011, 87, 679-702. [CrossRef]

58. Alagic, E.; Spildo, K.; Skauge, A.; Solbakken, J. Effect of crude oil ageing on low salinity and low salinity surfactant flooding. J. Pet. Sci. Eng. 2011, 78, 220-227. [CrossRef]

59. Sylte, J.E.; Hallenbeck, L.D.; Thimas, L.K.; Co, P.P. Ekofisk Formation Pilot Waterflood. In Proceedings of the SPE Annual Technical Conference and Exhibition, Houston, TX, USA, 2-5 October 1988; p. 18276.

60. Hamon, G. Another look at ekofisk wettability. In Proceedings of the International Symposium of the Society of Core Analysts, Abu Dhabi, United Arab Emirates, 5-9 October 2004; pp. 1-14. 
61. Amaefule, J.O.; Altunbay, M.; Tiab, D.; Kersey, D.G.; Keelan, D.K. Enhanced Reservoir Description: Using Core and Log Data to Identify Hydraulic (Flow) Units and Predict Permeability in Uncored Intervals/Wells. In Proceedings of the SPE Annual Techical Conference Exhibition Society of Petroleum Engineers, Houston TX, USA, 3-6 October 1993. [CrossRef]

62. Tang, X.; Zhou, W.Y.; Yang, W.L.; Zhang, C.; Zhang, C.M. An improved method in petrophysical rock typing based on mercuryinjection capillary pressure data. Energy Sources Part A Recover. Util. Environ. Eff. 2020. [CrossRef]

63. Mirzaei-Paiaman, A.; Ostadhassan, M.; Rezaee, R.; Saboorian-Jooybari, H.; Chen, Z. A new approach in petrophysical rock typing. J. Pet. Sci. Eng. 2018, 166, 445-464. [CrossRef] 